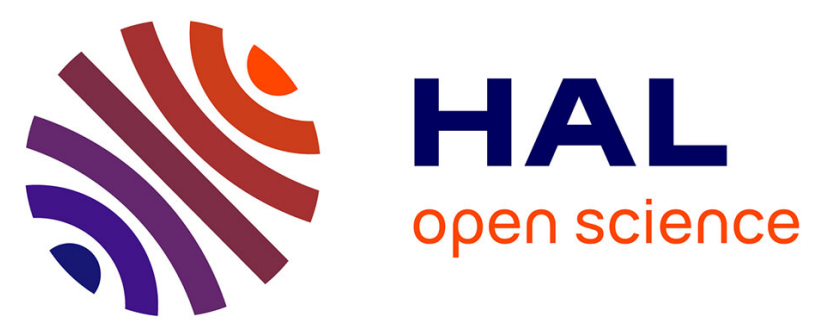

\title{
Behavioral and metabolic effects of sublethal doses of two insecticides, chlorpyrifos and methomyl, in the Egyptian cotton leafworm, Spodoptera littoralis (Boisduval) (Lepidoptera: Noctuidae)
}

Youssef Dewer, Marie-Anne Pottier, Lisa Lalouette, Annick Maria, Matthieu Dacher, Luc P. Belzunces, Guillaume Kairo, D Renault, Martine Maïbèche, David Siaussat

\section{- To cite this version:}

Youssef Dewer, Marie-Anne Pottier, Lisa Lalouette, Annick Maria, Matthieu Dacher, et al.. Behavioral and metabolic effects of sublethal doses of two insecticides, chlorpyrifos and methomyl, in the Egyptian cotton leafworm, Spodoptera littoralis (Boisduval) (Lepidoptera: Noctuidae). Environmental Science and Pollution Research, 2016, 23 (4), pp.3086-3096. 10.1007/s11356-015-5710-1 . hal-01231427

\section{HAL Id: hal-01231427}

\section{https://hal-univ-rennes1.archives-ouvertes.fr/hal-01231427}

Submitted on 24 Nov 2015

HAL is a multi-disciplinary open access archive for the deposit and dissemination of scientific research documents, whether they are published or not. The documents may come from teaching and research institutions in France or abroad, or from public or private research centers.
L'archive ouverte pluridisciplinaire HAL, est destinée au dépôt et à la diffusion de documents scientifiques de niveau recherche, publiés ou non, émanant des établissements d'enseignement et de recherche français ou étrangers, des laboratoires publics ou privés.

$$
\text { Copyright }
$$




\title{
Behavioral and metabolic effects of sublethal doses of two insecticides, chlorpyrifos and methomyl, in the Egyptian cotton leafworm, Spodoptera littoralis (Boisduval) (Lepidoptera: Noctuidae)
}

\author{
Youssef Dewer ${ }^{1} \cdot$ Marie-Anne Pottier ${ }^{2} \cdot$ Lisa Lalouette $^{2} \cdot$ Annick Maria $^{2}$ • \\ Matthieu Dacher ${ }^{2} \cdot$ Luc P. Belzunces ${ }^{4}$ - Guillaume Kairo ${ }^{4}$ - David Renault ${ }^{3}$. \\ Martine Maibeche ${ }^{2} \cdot$ David Siaussat $^{2}$
}

\begin{abstract}
Insecticides have long been used as the main method in limiting agricultural pests, but their widespread use has resulted in environmental pollution, development of resistances, and biodiversity reduction. The effects of insecticides at low residual doses on both the targeted crop pest species and beneficial insects have become a major concern. In particular, these low doses can induce unexpected positive (hormetic) effects on pest insects, such as surges in population growth exceeding what would have been observed without pesticide application. Methomyl and chlorpyrifos are two insecticides commonly used to control the population levels of
\end{abstract}

Responsible editor: Philippe Garrigues

Youssef Dewer and Marie-Anne Pottier contributed equally to this work.

Electronic supplementary material The online version of this article (doi:10.1007/s11356-015-5710-1) contains supplementary material, which is available to authorized users.

David Siaussat

david.siaussat@upmc.fr

1 Bioassay Research Department, Central Agricultural Pesticides Laboratory (CAPL), Sabahia Research Station, Agricultural Research Center (ARC), Sabahia, Baccous, P.O. Box 21616, Alexandria, Egypt

2 Institute of Ecology and Environmental Sciences of Paris (iEES Paris) - Sensory Ecology Department - UMR UPMC 113, CNRS, IRD, INRA, PARIS 7, Sorbonne Universités, UPMC Univ Paris 06, UPEC - 7 Quai Saint Bernard, F-75005 Paris, France

3 Université de Rennes 1, UMR CNRS 6553 Ecobio 263 Avenue du Gal Leclerc, CS 74205, 35042 Rennes, France

4 INRA, Laboratoire de Toxicologie Environnementale, UR 406 A\&E, 228 Route de l'Aérodrome, CS 40509, 84914 Avignon Cedex 9 , France the cotton leafworm Spodoptera littoralis, a major pest moth. The aim of the present study was to examine the effects of sublethal doses of these two pesticides, known to present a residual activity and persistence in the environment, on the moth physiology. Using a metabolomic approach, we showed that sublethal doses of methomyl and chlorpyrifos have a systemic effect on the treated insects. We also demonstrated a behavioral disruption of $S$. littoralis larvae exposed to sublethal doses of methomyl, whereas no effects were observed for the same doses of chlorpyrifos. Interestingly, we highlighted that sublethal doses of both pesticides did not induce a change in acetylcholinesterase activity in head of exposed larvae.

Keywords Spodoptera littoralis · Crop pest · Insecticide · Sublethal doses $\cdot$ Methomyl $\cdot$ Chlorpyrifos $\cdot$ Olfaction $\cdot$ Insect behavior

\section{Introduction}

Study of the effects of sublethal doses of neurotoxic chemicals has been poorly investigated until now, and their mechanisms of action are thus only partially understood. Yet, for several years, the policy of many countries has been to reduce the use of pesticides (Bellinder et al. 1994). Furthermore, it is well known that many biotic (e.g., plant uptake, microbial, and plant degradation) and abiotic (e.g., wind, volatilization, chemical degradation, and dripping) processes can spatially and temporally change the pesticide doses that an insect is exposed to in the field. It is therefore urgent to determine if environmentally relevant sublethal pesticide concentrations could have a positive or negative effect on non-target and target species. In a context of sustainable development, it also 
seems important to find new ways to assess the exposure of terrestrial ecosystems to low doses of pesticides and, in particular, to find new biomarkers (molecular to behavioral ones) for the survey of organisms living in these contaminated environments.

Some studies have reported positive effects of pesticide sublethal doses - also called hormetic effects - on population growth and reproductive physiology in various insect species, including in the cotton leafworm Spodoptera littoralis (review in Cutler 2012; Tricoire-Leignel et al. 2012). However, deleterious impacts of low doses were also reported on fecundity, longevity, and behavior (Ripper 1956; Haynes 1988; Stark and Banks 2003; Dewer and Mahmoud 2014). While the effects of high doses were easy to determine because they are usually associated with the mortality of the targeted species, effects of low and sublethal doses were more difficult to observe and are thus relatively less well studied (Cutler 2012).

Among a variety of insecticides, organophosphorus and carbamate compounds are widely used worldwide. Chlorpyrifos and methomyl are currently the two most used insecticides belonging to these pesticide families. Both of them cause severe cholinergic poisoning in insects by inhibiting the enzyme acetylcholinesterase $(\mathrm{AChE})$ that hydrolyzes the neurotransmitter acetylcholine. Overstimulation of the nervous system leads to the insect's death. Chlorpyrifos has a well-known environmental persistence and can be found in all environmental compartments (Delpuech et al. 1998). This pesticide induces an irreversible inhibition of AChE that can be long lasting even at low doses (Paudyal 2008; Carr et al. 1995). Indeed, one study highlighted that a short term application (i.e., $4 \mathrm{~h}$ ) of chlorpyrifos at sublethal doses continued to inhibit AChE for several days afterward (Carr et al. 1995). This effect was also reported for non-targeted species such as wolf spiders (Lycisidae) for which the AChE inhibition was observed 8 days after a 24- or 48-h exposure to chlorpyrifos (Van Erp et al. 2002). Exposure of the parasitoid Aphytis melinus to median lethal concentration (LC50) of chlorpyrifos reduced longevity and depressed progeny production (Rosenheim and Hoy 1988). As other carbamate insecticides, methomyl induces a reversible AChE inhibition. Contrary to chlorpyrifos, this product has a low persistence in the environment and a high toxicity not only for pest insects but also for birds, aquatic organisms, and beneficial arthropods such as bees (Van Scoy et al. 2013). Its use is often recommended against pests resistant to organophosphorus pesticides (WHO 1983). Few studies have demonstrated effects of methomyl at sublethal doses in insects: a stimulation of the fecundity was reported in a susceptible strain of the diamondback moth Plutella xylostella (Nemoto 1984), and a transitory growth reduction was observed in larvae of the fall armyworm Spodoptera frugiperda (Ross and Brown 1982).

These two insecticides were currently used to protect crops against the polyphagous larval stages of $S$. littoralis (Miles and Lysandrou 2002; Riskallah 1980). This noctuid moth is a worldwide economically important pest of cotton, vegetables, and ornamental crops. Pesticide-resistant populations cause severe problems in various countries, and the larvae cause high levels of damages (Smagghe et al. 2002). In this nocturnal insect, olfaction is the main sensory modality to communicate with mating partners, localize trophic patches, and oviposition sites, making this species a main pest insect model to decipher the functioning of its olfactory system, from genes to behavior (Bigot et al. 2012; Pottier et al. 2012; Party et al. 2013). Several studies have focused on the impact of sublethal doses of various pesticides on olfaction using pest insects as models (Tricoire-Leignel et al. 2012) in order to determinate if these products could act as info-disruptors by modifying the chemical communication system and thus decrease reproduction chances in target insects (Lurling and Scheffer 2007), or if they could act as hormetic factors by enhancing reproduction (Cutler 2012). However, none of these studies were conducted on S. littoralis. In addition, the effect of methomyl at sublethal doses on olfaction has not been studied yet in any insect species, whereas few data were available for chlorpyrifos. It has been shown that Trichogramma brassicae males exposed to chlorpyrifos at $\mathrm{LD}_{20}$ or $\mathrm{LD}_{0.1}$ were less arrested by female sexual pheromones (review in Desneux et al. 2007), whereas at $\mathrm{LD}_{20}$, it caused an increase in host searching in the parasitoid Leptopilina heterotoma (review in Desneux et al. 2007). These studies were restricted on adults.

In this context, the first step of this study was to determine the sublethal doses of methomyl and chlorpyrifos in $S$. littoralis larvae. To evaluate if these doses have indeed an effect on the insect physiology, we use a metabolomic approach to compare the levels of several hemolymphatic markers between control and treated larvae. In the second step, we examined the effects of sublethal doses of these two compounds on a vital olfactory-induced behavior (i.e., the attraction of larvae by food odors) and measured in the head of the corresponding larvae the AChE activity.

\section{Materials and methods}

\section{Insect rearing and insecticide treatments}

Spodoptera littoralis larvae were reared on a semi-artificial diet (Hinks and Byers 1976) at $24{ }^{\circ} \mathrm{C}, 60-70 \%$ relative humidity, and a 16:8 light/dark cycle until emergence. Topical applications of insecticides were performed on fourth larval instars using a micro-applicator (Hamilton $10 \mu \mathrm{L}$ syringe and Hamilton dispenser). A range of concentrations of chlorpyrifos (45395, SIGMA PESTANAL, France) diluted in hexane, or of methomyl (36159, SIGMA PESTANAL, France) diluted in dimethyl succinate, were applied to the larval cuticle 
between the fifth and sixth segment (counting starting from the first head segment). Control insects were treated using hexane or dimethyl succinate, respectively. Forty insects were exposed to each concentration of both compounds. Percentage of mortality was determined $24 \mathrm{~h}$ after pesticide application and $\mathrm{LD}_{50}$ calculated by probit analysis. For further metabolic fingerprinting and behavioral analyses, insects were exposed as described previously but using two chosen sublethal doses for each pesticide, i.e., $1 / 10$ and $1 / 100$ of the $\mathrm{LD}_{50}$ (noted $\mathrm{LD}_{50}{ }^{1 / 10}$ and $\mathrm{LD}_{50}{ }^{1 / 100}$ afterward). These doses did not induce any mortality.

\section{Metabolic fingerprinting}

The hemolymph of larvae was sampled as described in Bigot et al. (2012). Hemolymph from four larvae $(40 \pm 10 \mu \mathrm{L})$ was suspended in ethanol (400 $\mu$ l, purity $99.9 \%$, MERCK, France). Ten replicates were prepared for each experimental condition. Samples were prepared as described in Khodayari et al. (2013), with minor modifications. The samples were homogenized in $600 \mu \mathrm{L}$ of methanol-chloroform (2:1) using a bead-beating device (Retsch ${ }^{\mathrm{TM}}$ MM301, RetschGbmH, Haan, Germany). Four hundred microliters of ice-cold ultrapure water was added, and then aliquots $(300 \mu \mathrm{L})$ of the upper aqueous phase containing polar metabolites were transferred to micro-tubes and vacuum-dried. Following derivatization (see (Khodayari et al. 2013) for the detailed experimental procedure), metabolites were analyzed by gas chromatography-mass spectrometry (GC-MS) (Figs. 1 and 2), which included a CTC CombiPal autosampler (GERSTEL GmbH \& Co.KG, Mülheim an der Ruhr, Germany), a Trace GC Ultra chromatograph, and a Trace DSQII quadruple mass spectrometer (Thermo Fischer Scientific Inc., Waltham, MA, USA) (Khodayari et al. 2013). Fiftyseven metabolites were analyzed (see supplementary data). Peaks were accurately annotated using both mass spectra (two specific ions) and retention times. Calibration curves were set using samples consisting of 58 pure references. Metabolite levels were quantified using XCalibur v2.0.7 software (Thermo Fisher Scientific Inc., Waltham, MA, USA).

\section{Behavioral experiments}

The ability of larvae to orient toward food odor was tested using a four-choice olfactometer (Analytical Research Systems, Inc, Florida, USA). Each internal odor source adaptors (OSA) with insect isolation trap was connected to the four cardinal corners of the arena in order to send the airflow (with or without odor) to the larvae placed on a fine mesh grid in the center of the arena. The air flow was generated using an air compressor (OLFM-4C-ADS, Analytical Research Systems, Inc, Florida, USA), pulsed in each OSA at $200 \mathrm{ml} / \mathrm{min}$ and regulated with a flow-meter. A vacuum flow evacuated odors through the grid in the center of the arena.
For feeding stimulation, a piece of semi-artificial diet was heated for $10 \mathrm{~s}$ in a microwave in order to increase the number of volatiles emitted by the food and then placed immediately in one of the four OSAs before air flow activation. The three other OSAs without food corresponded to air flow controls. The arena was cleaned regularly with $10 \%$ TFD4 (Dutscher, France) to eliminate odor residues. The location of the OSA containing the food was changed between each test in order to prevent any innate preferences for particular parts of the arena. Analyses were performed under red light conditions $(\mathrm{T}=22 \pm$ $1{ }^{\circ} \mathrm{C}, \mathrm{RH}=70 \pm 10 \%$ ) and recorded over a 1 -h period with a CC infrared light-sensitive camera (QuickCam ${ }^{\circledR}$ Pro 9000).

For each experiment, ten larvae (fourth instar) were isolat$\mathrm{ed}$, food deprived for $24 \mathrm{~h}$, and then introduced into the central starting zone (noted SZ) of the arena (see Figs. 3 and 4). Larvae were considered as non-activated when staying in SZ for the duration of the test. Movements of the activated larvae were tracked individually in the four quadrants corresponding to the four airflow stimulations. Each quadrant was divided in two zones: a pre-zone (noted Z) and a target zone (noted C). The quadrant corresponding to the odor stimulation was noted ( $\mathrm{C} 0$ and $\mathrm{Z} 0$ ), then the three control quadrants with air flow alone were noted ( $\mathrm{C} 1$ and $\mathrm{Z} 1 ; \mathrm{C} 2$ and $\mathrm{Z2} ; \mathrm{C} 3$ and $\mathrm{Z} 3$ ) following the reverse rotation clockwise (see Figs. 3 and 4). Several parameters were then measured: the time spent in the nine designated sectors of the arena, the proportion of larvae reaching the target, and the speed of each larva. As the insect isolation trap connected to the OSA, insects entering the target zone were not able to move out of this zone.

\section{AChE extraction and assays}

AChE was extracted from the head removed from anesthetized adults of $S$. littoralis. For each sample, 5 heads were weighted, and extraction buffer $(10 \mathrm{mM} \mathrm{NaCl}$ and $40 \mathrm{mM}$ sodium phosphate $\mathrm{pH} 7.4$ containing $1 \%(w / v)$ Triton $\mathrm{X}-100,2 \mu \mathrm{g} / \mathrm{mL}$ antipain, leupeptin, and pepstatin $\mathrm{A}, 25$ units $/ \mathrm{mL}$ aprotinin, and $0.1 \mathrm{mg} / \mathrm{mL}$ soybean trypsin inhibitor as protease inhibitors[1]) was added to obtain $10 \%(w / v)$ extract. Tissues were homogenized using a high-speed homogenizer Tissue Lyser II (Qiagen ${ }^{\circledR}$ ), for 5 periods of $10 \mathrm{~s}$ with oscillation frequencies of $30 \mathrm{~Hz}$ at $30 \mathrm{~s}$ intervals. This procedure was performed twice with $10 \mathrm{~min}$ interval before the extraction product was centrifuged for $20 \mathrm{~min}$ at $15,000 \mathrm{~g}$. Supernatants were removed for analysis. All of the extraction procedure and sample conservation were performed at $4{ }^{\circ} \mathrm{C}$. For each sample, AChE assay was performed in triplicate with $10 \mu \mathrm{l}$ of enzyme extract. The final concentrations of the reagents in the reaction medium were $0.3 \mathrm{mM}$ AcSCh.I, $1.5 \mathrm{mM}$ DTNB, and $100 \mathrm{mM}$ sodium phosphate buffer at $\mathrm{pH} 7.0$, following the method of Ellman et al. (1961) modified by Belzunces et al. (1988). AChE activity was 
$\mathrm{nmol} / \mu \mathrm{l}$ hemolymph

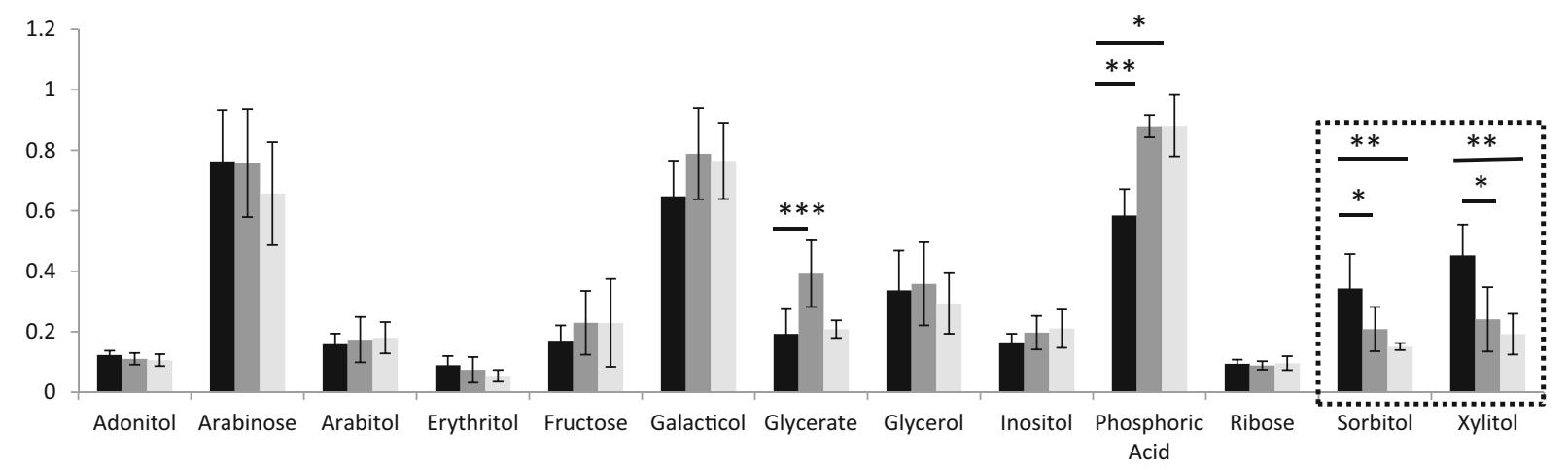

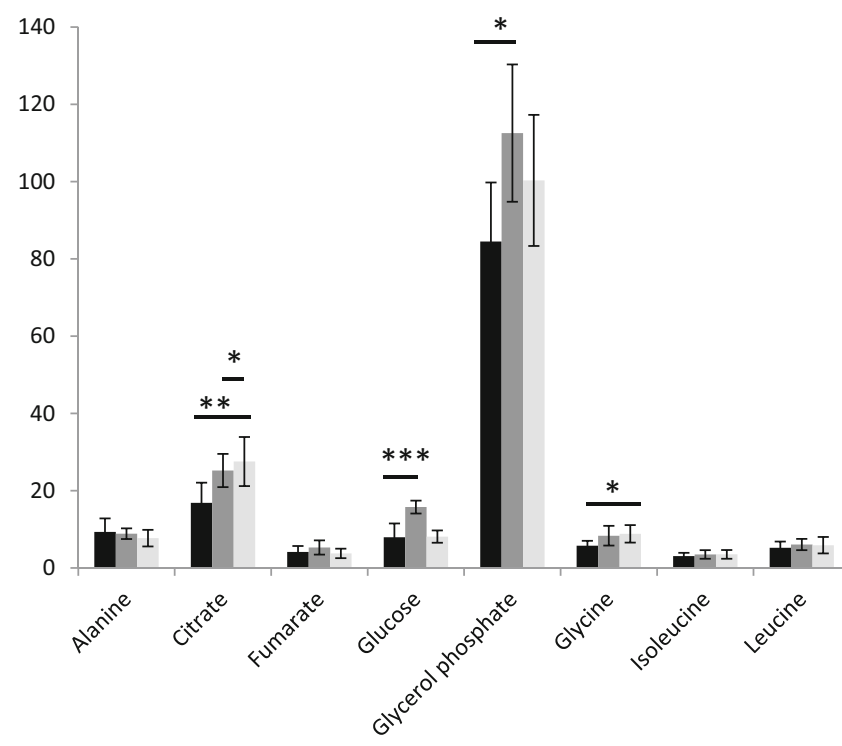

Fig. 1 Metabolite contents of hemolymph from chlorpyrifos-treated S. littoralis fourth instar larvae. Twenty-four hours following dorsal topical application of chlorpyrifos at $\mathrm{LC}_{50}{ }^{1 / 10}$ and $\mathrm{LC}_{50}{ }^{1 / 100}$, and hemolymphs of four larvae were collected, pooled, and analyzed by GC-MS. Metabolite contents (nmoles $\mu \mathrm{L}^{-1}$ of hemolymph) were expressed as means $\pm \mathrm{SE}$ ( $N=10$ replicates for each experimental

spectrophotometrically measured at $412 \mathrm{~nm}$ for $15 \mathrm{~min}$ using a TECAN infinite ${ }^{\circledR}$ F500 plate reader.

\section{Statistical analyses}

Lethal doses for $50 \%$ of the population $\left(\mathrm{LD}_{50}\right)$ were computed using probit analyses with an $\alpha$ risk of 0.05 (MINITAB Inc., State College, PA, USA). Comparisons of behavioral experiments were analyzed using a Kruskal-Wallis one-way analysis of variance. For metabolic variations and AChE activity, we performed a one-way ANOVA to compare the treatments (i.e., the control group and the two treated groups) for each pesticide. We used the ImPerm package in R 3.2 to compute the $p$ values through a permutation procedure, which allows us to use ANOVA without the need of having normal data (Venables and Ripley 2000). These statistical analyses were conducted using Minitab ${ }^{\text {тм }} 13$ statistical software
- Hexane (control)

- Chlorpyrifos, $\mathrm{LD}_{50}{ }^{1 / 100}$

Chlorpyrifos, $\mathrm{LD}_{50}{ }^{1 / 10}$ condition). Single asterisk indicates a significant difference $(p<0.05)$ between control and pesticide treated, double and triple asterisk indicates more significant differences ( $p<0.01 ; p<0.0001$, respectively). Dotted squares highlight metabolites that present significant differences between control and treated larvae and specific to chlorpyrifos treatment

(MINITAB Inc., State College, PA, USA), STATISTICA (StatSoft Enterprise, USA), and R software.

\section{Results}

\section{LD determination}

The chlorpyrifos and methomyl doses that yielded $50 \%$ mortality in fourth larval instar $S$. littoralis following dorsal topical application were $0.31 \pm 0.061 \mu \mathrm{g}$ and $0.057 \pm 0.0053 \mu \mathrm{g}$, respectively.

\section{Sublethal dose effects on hemolymphatic metabolite concentrations}

$\mathrm{LD}_{50}{ }^{1 / 10}$ and $\mathrm{LD}_{50}{ }^{1 / 100}$ of chlorpyrifos and methomyl were used to determine their potential systemic effects 


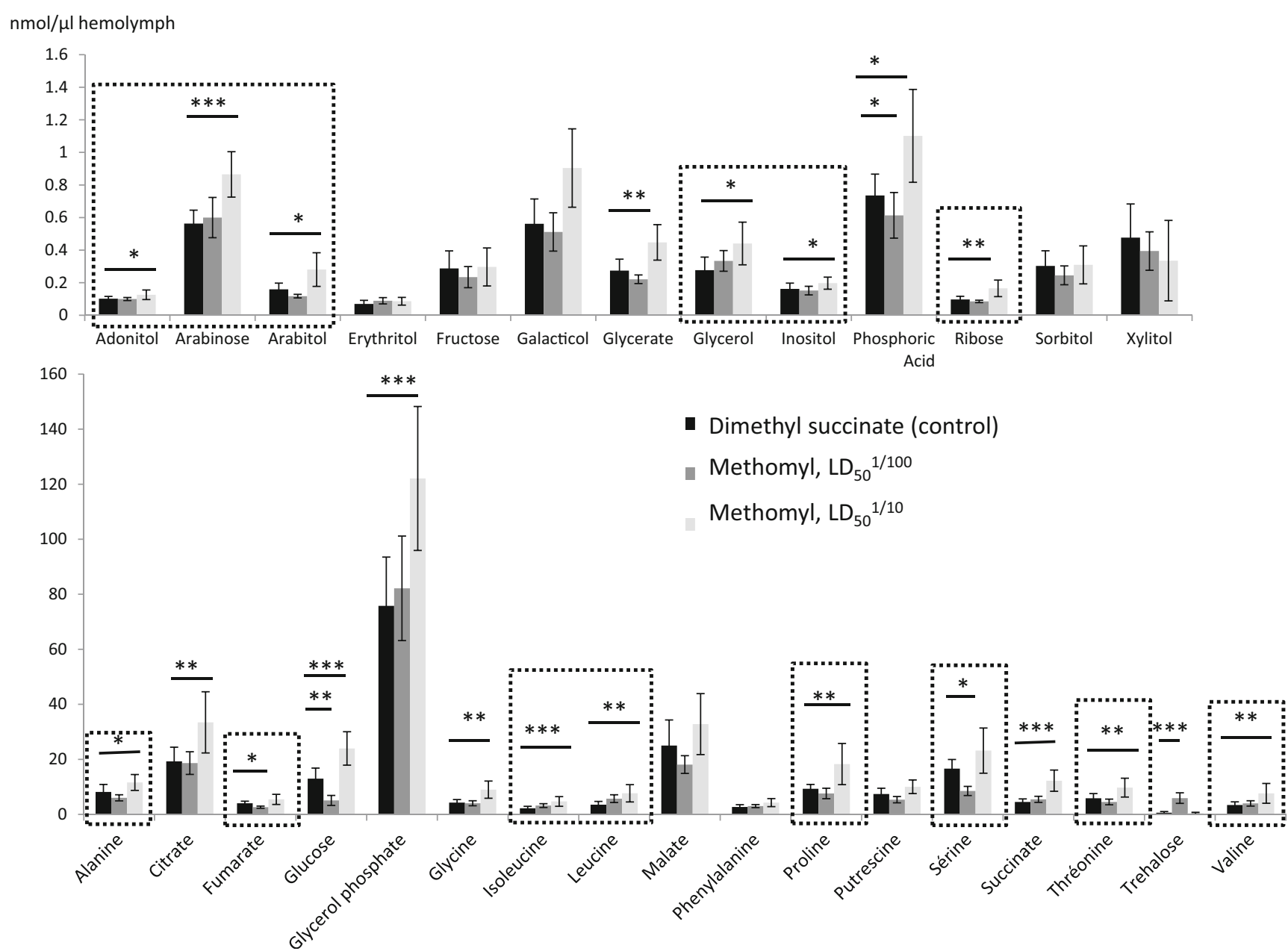

Fig. 2 Metabolite contents of hemolymph from methomyl-treated $S$. littoralis fourth instar larvae. Twenty-four hours following dorsal topical application of methomyl at $\mathrm{LC}_{50}{ }^{1 / 10}$ and $\mathrm{LC}_{50}{ }^{1 / 100}$ in fourth larval instar, the pooled hemolymph of four larvae was collected and analyzed by GC-MS. Metabolite contents (nmoles $\mu \mathrm{L}^{-1}$ of hemolymph) were expressed as means $\pm \mathrm{SE}(N=10$ replicates for each experimental condition). Single asterisk indicates a significant difference $(p<0.05)$ between control and pesticide treated, double and triple asterisk indicates more significant differences ( $p<0.01 ; p<0.0001$, respectively). Dotted squares highlight metabolites that present significant differences between control and treated larvae and specific to methomyl treatment

application. Indeed, whereas chlorpyrifos exposure induced significant circulating level changes for only three polyols (i.e., xylitol, sorbitol, and glycerol-3-phosphate; Fig. 1), methomyl exposure altered a larger number of metabolites including several amino acids (i.e., valine, leucine, isoleuscine, proline, serine), two sugars (i.e., ribose and arabinose), one polyol (i.e., arabitol), and fumarate, which is an intermediate of the citric acid cycle (Fig. 2).

\section{Effects of sublethal doses on the larval behavior}

The proportion of time spent by the larvae in the different pre-defined zones of the four-choice olfactometer arena was calculated for each larva $24 \mathrm{~h}$ after application of the two sublethal doses for both pesticide or of the corresponding solvent for the controls (Figs. 3 and 4). Compared to the 

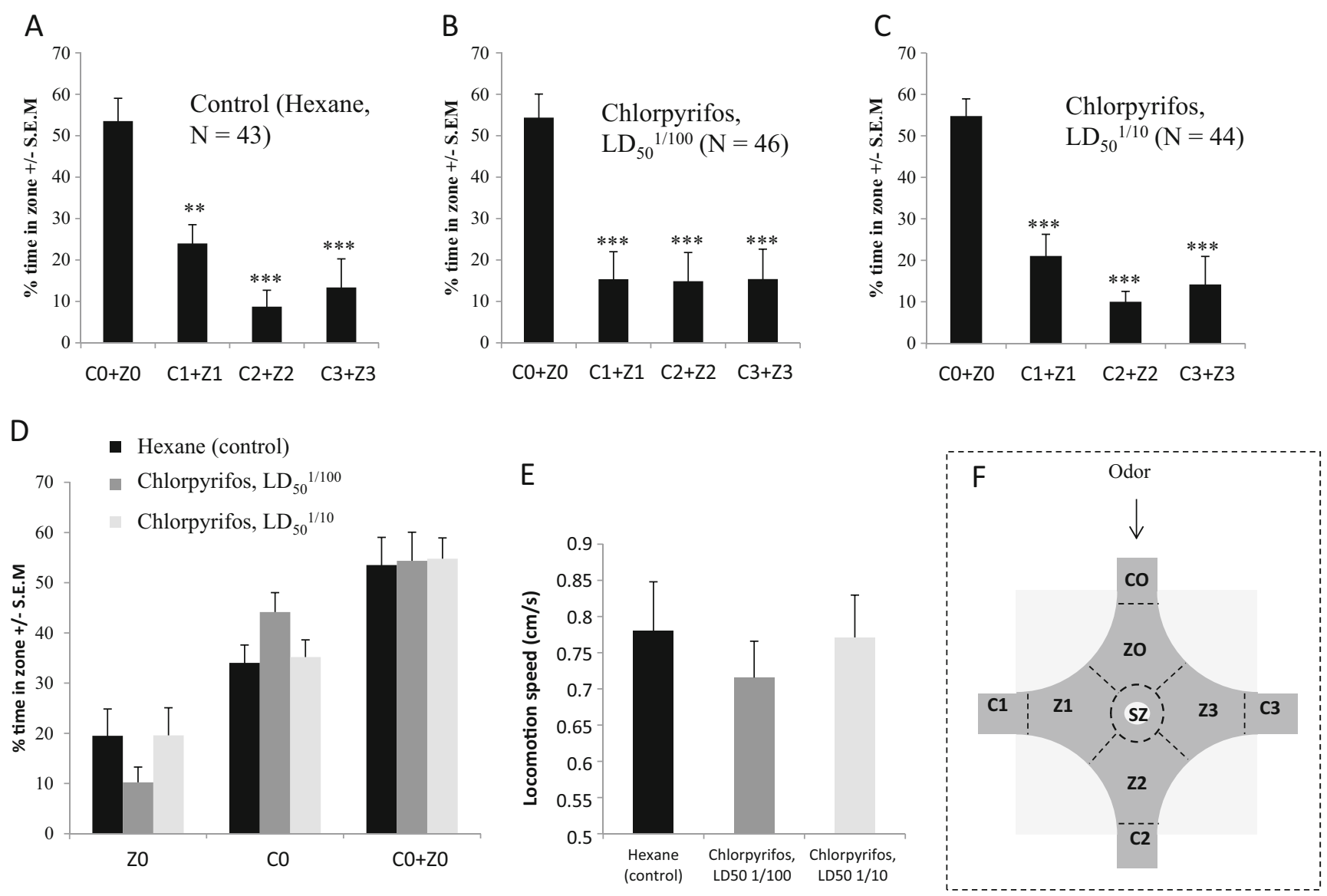

Fig. 3 Behavioral responses of $S$. littoralis fourth instar larvae exposed to chlorpyrifos sublethal doses. Twenty-four hours following dorsal topical application of chlorpyrifos at $\mathrm{LC}_{50}{ }^{1 / 10}$ and $\mathrm{LC}_{50}{ }^{1 / 100}$, and the percentage of time spent by pesticide-treated and control (hexane) larvae in

designated quadrants of the arena were calculated (mean \pm SEM). Single asterisk indicates a significant difference $(p<0.05)$ between odorant target and other zones, double and triple asterisk indicates more significant differences $(p<0.01 ; p<0.0001$, respectively)

control insects (Fig. 3a), chlorpyrifos at $\mathrm{LD}_{50}{ }^{1 / 10}$ and $\mathrm{LD}_{50}{ }^{1 / 100}$ did not alter the larval odorant-induced behaviors (Fig. 3b, c) since (i) the proportions of time spent in the odorant zones $(\mathrm{C} 0+\mathrm{Z} 0)$ were largely higher than and significantly different to the three other zones $(\mathrm{C} 1+\mathrm{Z} 1, \mathrm{C} 2+\mathrm{Z} 2$, and $\mathrm{C} 3+\mathrm{Z3}$ ), and (ii) the times spent in $\mathrm{Z} 0$ and $\mathrm{C} 0$ odorant zones were similar for the control and the treated insects (Fig. 3d). However, a different response was observed for larvae exposed to methomyl at $\mathrm{LD}_{50}{ }^{1 / 10}$ (Fig. 4). Indeed, larvae exposed to this dose spent more time than the controls in zones without odor stimulation (Fig 4c), whereas no differences were observed for larvae exposed to $\mathrm{LD}_{50}{ }^{1 / 100}$ (Fig. $4 \mathrm{a}, \mathrm{b}$ ). Moreover, $\mathrm{LD}_{50}{ }^{1 / 10}$-treated larvae spent less time in odorant $(\mathrm{C} 0+\mathrm{Z} 0)$ zones compared both to the control and to the $\mathrm{LD}_{50}{ }^{1 / 100}$-treated larvae (Fig 4d). As the locomotor speed of larvae in all experimental conditions showed no significant differences for both pesticides (Figs. 3 and 4e), we can conclude that methomyl, at least at the higher dose of $\mathrm{LD}_{50}{ }^{1 / 10}$, disrupts the attraction of treaded larvae by food odors, whereas chlorpyrifos at the two chosen doses did not alter the attraction of larvae by food odors.

\section{Effects of sublethal doses on the AChE activity}

AChE activity was determined in the head of larvae exposed to the two sublethal doses of both pesticide or to the corresponding solvent for the controls, $24 \mathrm{~h}$ after pesticide applications (Fig. 5). The results showed that larvae exposed to sublethal doses of methomyl and chlorpyrifos have an AChE activity similar to that of controls (no significant difference).

\section{Discussion}

Our results highlight for the first time the effects of sublethal doses of methomyl and chlorpyrifos on $S$. littoralis larvae, both at the systemic and behavioral levels. Few data were available to date on the effect of these two insecticides on species from the Spodoptera genus. Moreover, all these studies were focused on lethal dose effects (Klein et al. 1982) and on resistance development. Resistance to chlorpyrifos has been shown in Salix exigua (Ishtiaq and Saleem 2011; Che et al. 2013), Spodoptera frugiperda (Carvalho et al. 2013), Spodoptera litura (Huang et al. 2011), and 

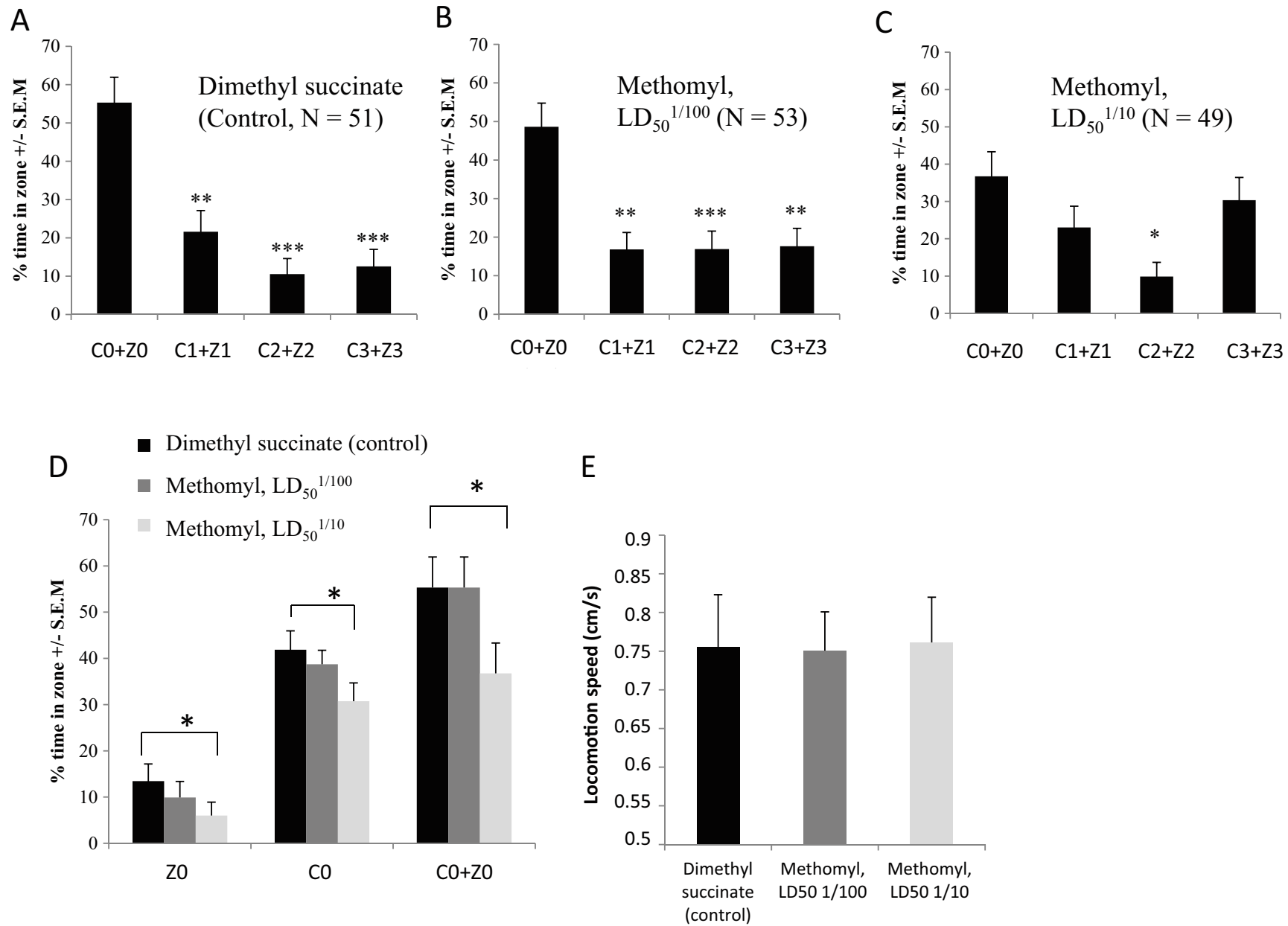

Fig. 4 Behavioral responses of $S$. littoralis fourth instar larvae exposed to methomyl sublethal doses. Twenty-four hours following dorsal topical application of methomyl at $\mathrm{LC}_{50}{ }^{1 / 10}$ and $\mathrm{LC}_{50}{ }^{1 / 100}$ in fourth larval instar, and percentage of time larvae spent in designated quadrants of

the arena were calculated for pesticide-treated larvae and control (hexane) (mean $\pm \mathrm{SEM})$. Single asterisk indicates a significant difference $(p<0.05)$ between target and other zones, double and triple asterisk indicates more significant differences ( $p<0.01 ; p<0.0001$, respectively)

S. littoralis (Miles and Lysandrou 2002). Resistance to methomyl in S. exigua (Byrne and Toscano 2001), S. frugiperda (Rios-Diez et al. 2011), S. litura (Tong et al.

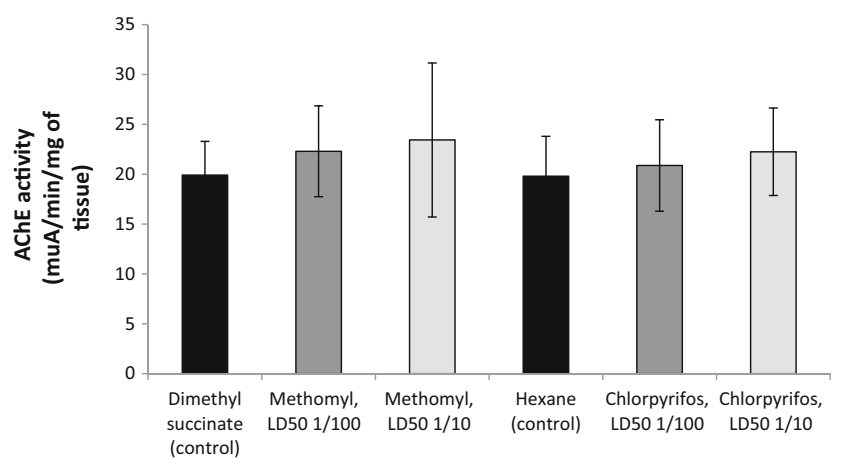

Fig. $5 \mathrm{AChE}$ activity in $S$. littoralis fourth instar larvae exposed to methomyl or chlorpyrifos sublethal doses. Twenty-four hours following dorsal topical application of methomyl or chlorpyrifos at $\mathrm{LC}_{50}{ }^{1 / 10}$ and $\mathrm{LC}_{50}{ }^{1 / 100}$ in fourth larval instar, AChE activity in head of larvae was determined. (mean \pm SEM)
2004; Saleem et al. 2008), and S. littoralis (Riskallah 1980) was observed.

The toxicological approach we used allowed first the determination of the median lethal doses which induced $50 \%$ of mortality $\left(\mathrm{LD}_{50}\right)$ for the two molecules. Despite the lack of previous toxicological data for chlorpyrifos and methomyl in S. littoralis, the $\mathrm{LD}_{50}$ values we found here for both products were consistent with those previously reported for the related species S. exigua and Helicoverpa zea (Pérez et al. 2000).

We then observed a disruption in metabolic homeostasis, as depicted by hemolymphatic alterations of several metabolite concentrations (Fig. 6). Chlorpyrifos exposure specifically induced a decrease of two polyols (xylitol and sorbitol) and an increase of glycerol-3-phosphate concentrations. Polyols and more particularly xylitol and sorbitol are involved in the pentose phosphate pathway (Kanfer et al. 1960; Bánhegyia et al. 1997; Jeffery and Jörnvall 1983). Glycerol-3-phosphate is involved in glycolysis and triacylglycerol production (AlvesBezerra and Gondim 2012). Thus, our results highlighted that 
Fig. 6 Schematic representation of the metabolic pathway disrupted by an exposure to methomyl or chlorpyrifos sublethal doses in S. littoralis fourth instar larvae. Metabolites presenting a hemolymphatic disruption compared to control were labeled $M$ when the disruption was observed following an exposure to sublethal doses of methomyl, $C$ for chlorpyrifos, and $B$ when it was observed for both pesticides

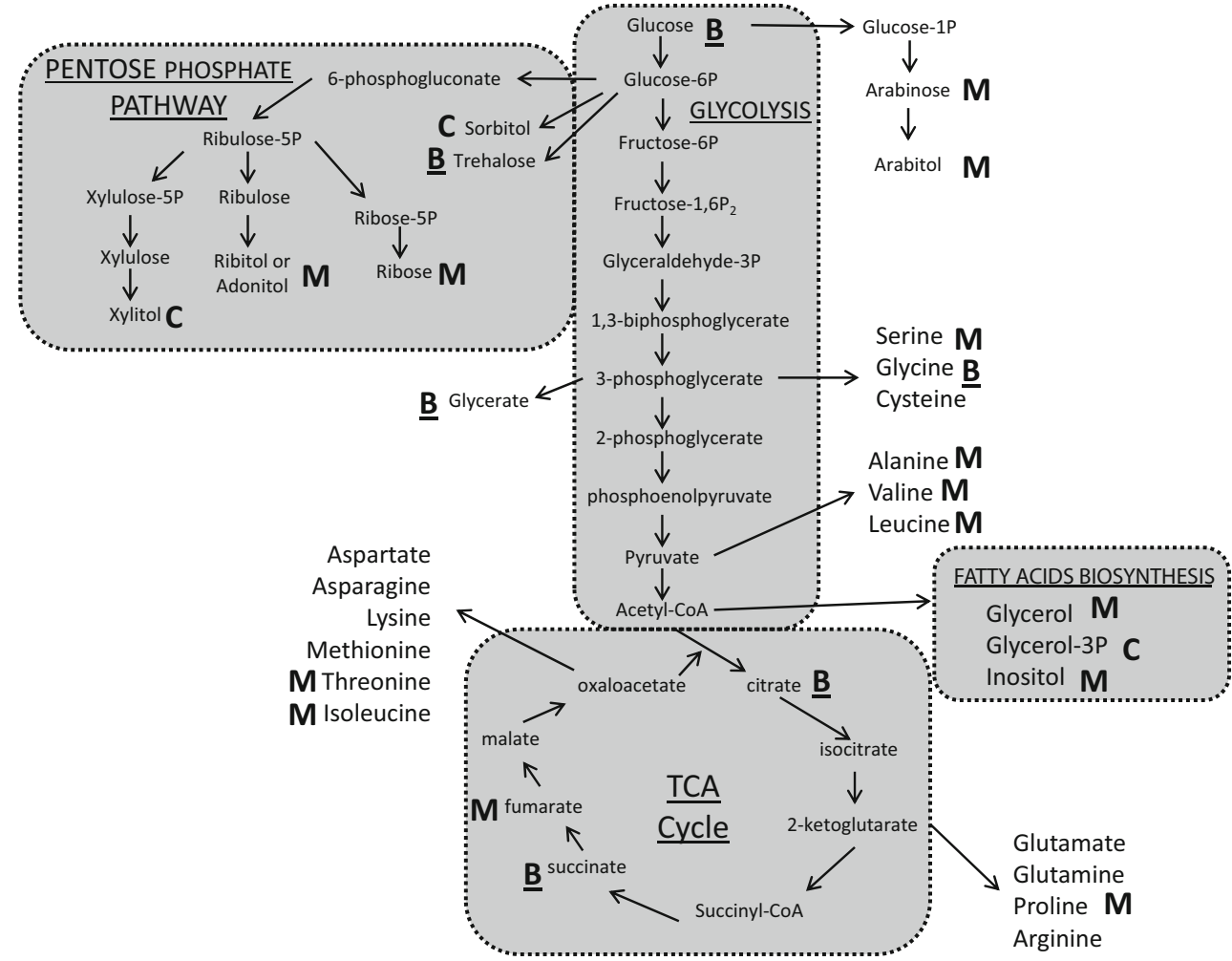

serum and urine after sublethal exposure to propoxur also demonstrated an alteration of metabolites involved not only in amino acid metabolism but also in energy (Liang et al. 2012a, b). In the earthworm Eisenia fetida, a decrease in phenylalanine, tyrosine lysine, alanine, valine, and leucine has been proposed as a potential metabolic response indicator to carbaryl sublethal exposure, since no significant change in metabolic profile was observed after exposure to sublethal doses of chlorpyrifos (McKelvie et al. 2011). Our results in S. littoralis are thus consistent with the literature available in other taxons and confirm that these metabolic pathways can be used as biomarkers of carbamate exposure.

Previous data and our current findings showed that disruption of energy production seems to be a common denominator in the metabolic responses of all species exposed to methomyl and chlorpyrifos, whatever the dose used. It is therefore not so surprising to observe here variations of metabolites involved in energetic pathways, as revealed by the increases in glycerol-3-phosphate (glycolysis and triacylglycerol production), glycerate (a glycolysis intermediate), citrate, and succinate (citric acid cycle) and glucose levels. Modifications in succinate and citrate levels can be due to a possible disruption in function of the citrate synthase or of the succinate dehydrogenase enzymes (Tripathi and Sharma 2005; Naqvi and Vaishnavi 1993). The concomitant increase of glucose, glycerate, and glycerol-3-phosphate highlighted a glycolysis disruption probably also due to enzymatic dysfunction. Interestingly, glycerol-3-phosphate appeared in bumblebee to be 
the optimal oxidative substrates for maintaining the high rates of oxidative metabolism of the mitochondria (Syromyatnikov et al. 2013).

We also observed an increase of phosphoric acid and trehalose concentrations after exposure to sublethal doses of chlorpyrifos and methomyl. Phosphoric acid is crucial for numerous cellular functions such as DNA and membrane lipid synthesis, generation of high-energy phosphate esters, and intracellular signaling. In Drosophila melanogaster, an increase in hemolymphatic phosphate has been associated with a reduction of life span and impaired functioning of Malpighian tubules (Bergwitz et al. 2013). A metabolomic study in earthworm has highlighted an increase of phosphoric acid after exposure to carbofuran at sublethal dose (Mudiam et al. 2013). Although it is difficult to determine the role of this metabolite in these contexts, it appeared to be a biomarker of exposure to two pesticides. Trehalose levels, the prominent "blood sugar" in most insect species (Thompson 2003), have already been found to increase in Bombyx mori and S. litura following exposure to sublethal doses of various pesticides (Nath 2003; Etebari et al. 2007; Zhu et al. 2012), suggesting that this sugar serves a protective role for proteins and cellular membranes from inactivation and/or denaturation (Elbein et al. 2003).

Few studies have been previously performed on the effect of these two pesticides on insect behavior. For chlorpyrifos, alterations of odorant-driven behaviors in the two parasitoid species $T$. brassicae and L. heterotoma were already reported but for higher doses (i.e., low lethal doses $\mathrm{LD}_{20}$ or $\mathrm{LD}_{0.1}$ (Desneux et al. 2007). Moreover, the impact of sublethal doses of methomyl on such olfactory-driven behavior has not been studied before. High doses of methomyl were only described to have feeding cessation effects (Hannig et al. 2009). We showed here evidence for disruption of larval behavior after methomyl exposure, whereas no modification was observed with chlorpyrifos. We can hypothesize that this behavioral alteration could be due to a modification in the detection of the odorant source at the peripheral olfactory level (i.e., the antennae) and/or in the perception of the stimulus at the olfactory central level (antennal lobes) and/or higher central nervous system structures integrating chemical cues. Although we do not have data on the toxicity of the two pesticides on the AChE activity at the time of the pesticide exposure, our results showed that $24 \mathrm{~h}$ after treatment, the AChE activity of treated and control larvae is similar. Our data did not allow us to establish if there is a reversibility of AChE inhibition or if sublethal doses cannot induce AChE inhibition in our model. But, at the time of the behavioral experiment, no cholinergic poisoning by disruption of AChE was observed unlike other studies (El Hassani et al. 2005; Benzidane et al. 2010; Paudyal 2008; Carr et al. 1995).

This behavioral disruption could also be due to an indirect consequence of metabolic disruption. Indeed, blocking or inhibiting neurotransmission can induce stress or/and metabolic modulation in neuronal tissues or tissues under neuronal control such as, for example, muscles. Bendahou and coworkers highlighted, for example, biochemical effects of sublethal doses of two neurotoxic pesticides (cypermethrin and fenitrothion) in hemolymph, head, and thoracic muscles of honeybees. Kokushi et al. (2013) correlated the high increase of metabolic ammonia levels after exposure to high concentration of chlorpyrifos to a severe convulsion in muscle caused by the inhibition of acetylcholinesterase activity. Moffat et al. (2015) highlighted that the poor navigation and foraging observed in bumblebee (Bombus terrestris) colonies following a chronic exposure of neonicotinoid can be explained by a mitochondrial dysfunction in the brain of these insects, which may affect more globally the cellular metabolism. Although the mechanisms are not well understood or studied, all these results suggest that low or sublethal doses of neurotoxic pesticides can probably disrupt the metabolism of many tissues under AChE control including the nervous system itself. However, since our metabolic profiling results were obtained with hemolymph of larvae, it is difficult to determine the tissue(s) responsible for this metabolic disruption.

As we have performed topical applications directly on larval cuticle, both pesticides could have escape from midgut detoxification processes, leading to the observed metabolic disruption. But, interestingly, despite these two insecticides sharing the same mode of action by inhibiting both AChE, sublethal doses of chlorpyrifos did not induce any behavioral disruption in our assay conditions. These specific responses may not only be due to differences in the efficacy of these substances, but may also be linked to the different detoxification capacities of the insect toward these compounds, especially at the hemolymph-brain barrier level. As in vertebrates and for other biological barriers (e.g., digestive epithelium), this barrier provides xenobiotic chemoprotection (Mayer et al. 2009; Limmer et al. 2014) and involved specific detoxification enzymes. We can hypothesize that the behavioral effects observed here can be due to lower defense capabilities of this hemolymph-brain barrier against methomyl compared to chlorpyrifos.

The metabolic disruption and the info-disruption of the chemical communication that we reported here in a model pest moth participate to a better understanding of the subtle effects of environmentally relevant sublethal pesticide concentrations on a target species. Further studies could allow to test if the effects observed here were observable in field conditions and to validate the metabolic markers identified here in an integrated pest management or ecotoxicological context.

Acknowledgments We thank Dr. Thomas Chertemps for his assistance in the statistical analyses. Dr. Lisa Lalouette was supported by a DIM ASTREA (Région Ile de France) post-doctoral fellowship. Dr. Youssef Dewer was supported by a "Mairie de Paris" post-doctoral fellowship: 
Call 2010, Imhotep exchange program grant (Campus France): Call 2011, and the French Embassy in Egypt post-doctoral fellowship 2012. Dr Marie-Anne Pottier and all experiments were supported by an "EMERGENCE" grant from the University Pierre and Marie Curie (UPMC-Paris 6) and PHEROTOX grant from ANR Bioadapt.

\section{References}

Alves-Bezerra M, Gondim KC (2012) Triacylglycerol biosynthesis occurs via the glycerol-3-phosphate pathway in the insect Rhodnius prolixus. Biochim Biophys Acta 1821(12):1462-71

Bánhegyia G, Brauna L, Csalaa M, Puskása F, Mandla J (1997) Ascorbate metabolism and its regulation in animals. Free Radic Biol Med 23(5):793-803

Begum G (2004) Carbofuran insecticide induced biochemical alterations in liver and muscle tissues of the fish Clarias batrachus (linn) and recovery response. Aquat Toxicol 66(1):83-92

Bellinder RR, Gummesson G, Karlsson C (1994) Percentage-driven government mandates for pesticide reduction: the Swedish model. Weed Technol 8(2):350-359

Belzunces LP, Toutant JP, Bounias M (1988) Acetylcholinesterase from apis-mellifera head-evidence for amphiphilic and hydrophilic forms characterized by triton X-114 phase-separation. Biochem J 255:463-470

Benzidane Y, Touinsi S, Motte E, Jadas-Ecart A, Communal P-Y, Leduc L, Thany SH (2010) Toxicity of thiamethoxam on cockroach locomotor activity associated to its metabolite clothianidin. Pest Manag Sci 66:1351-1359

Bergwitz C, Wee MJ, Sinha S, Huang J, Derobertis C, Mensah LB, Cohen J, Friedman A et al (2013) Genetic determinants of phosphate response in Drosophila. Plos ONE 8(3):e56753

Bigot L et al (2012) Peripheral regulation by ecdysteroids of olfactory responsiveness in male Egyptian cotton leaf worms, Spodoptera littoralis. Insect Biochem Mol Biol 42(1):22-31

Byrne FJ, Toscano NC (2001) An insensitive acetylcholinesterase confers resistance to methomyl in the beet armyworm Spodoptera exigua (Lepidoptera: Noctuidae). J Econ Entomol 94(2):524-8

Carr RL, Straus DL, Chambers JE (1995) Inhibition and aging of channel catfish brain acetylcholinesterase following exposure to two phosphorothionate insecticides and their active metabolites. J Toxicol Environ Health 45(3):325-36

Carvalho RA, Omoto C, Field LM, Williamson MS, Bass C (2013) Investigating the molecular mechanisms of organophosphate and pyrethroid resistance in the fall armyworm Spodoptera frugiperda. PLoS One 8(4):e62268

Che W, Shi T, Wu Y, Yang Y (2013) Insecticide resistance status of field populations of Spodoptera exigua (Lepidoptera: Noctuidae) from China. J Econ Entomol 106(4):1855-62

Cutler GC (2012) Insects, insecticides and hormesis: evidence and considerations for study. Dose-Response 11(2):154-177

Delpuech JM, Gareau E, Terrier O, Fouillet P (1998) Sublethal effects of the insecticide chlorpyrifos on the sex pheromonal communication of Trichogramma brassicae. Chemosphere 36(8):1775-1785

Desneux N, Decourtye A, Delpuech JM (2007) The sublethal effects of pesticides on beneficial arthropods. Annu Rev Entomol 52:81-106

Dewer Y, Mahmoud M (2014) Effectiveness and safety of some essential oils of aromatic plants on the growth and silk production of the silkworm Bombyx mori. L. J Entomol Zool Stud 2(2):81-86

Elbein AD, Pan YT, Pastuszak I, Carroll D (2003) New insights on trehalose: a multifunctional molecule. Glycobiology 13(4):17-27
El Hassani AK, Dacher M, Gauthier M, Armengaud C (2005) Effects of sublethal doses of fipronil on the behavior of the honey-bee (Apis mellifera). Pharmacol Biochem Behav 82:30-39

Ellman GL, Courtney KD, Andres Junior V, Feather-Stone R (1961) A new and rapid colorimetric determination of acetylcholinesterase activity. Biochem Pharmacol 7:88-95

Etebari K, Bizhannia AR, Sorati R, Matindoost L (2007) Biochemical changes in hemolymph of silkworm larval due to pyriproxyfen residue. Pestic Biochem Physiol 88:14-19

Hannig GT, Ziegler M, Marçon PG (2009) Feeding cessation effects of chlorantraniliprole, a new anthranilic diamide insecticide, in comparison with several insecticides in distinct chemical classes and mode-of-action groups. Pest Manag Sci 65(9):969-74

Haynes K (1988) Sublethal effects of neurotoxic insecticides in insect behavior. Annu Rev Entomol 33:149-68

Hinks CF, Byers JR (1976) Biosystematics of the genus Euxoa (Lepidoptera: Noctuidae). V. Rearing procedures and life cycles of 36 species. Can Entomol 108:1345-1357

Huang Y, Xu Z, Lin X, Feng Q, Zheng S (2011) Structure and expression of glutathione $S$-transferase genes from the midgut of the common cutworm, Spodoptera litura (Noctuidae) and their response to xenobiotic compounds and bacteria. J Insect Physiol 57(7):1033-44

Ishtiaq M, Saleem MA (2011) Generating susceptible strain and resistance status of field populations of Spodoptera exigua (Lepidoptera: Noctuidae) against some conventional and new chemistry insecticides in Pakistan. J Econ Entomol 104(4):1343-8

Jeffery J, Jörnvall H (1983) Enzyme relationships in a sorbitol pathway that bypasses glycolysis and pentose phosphates in glucose metabolism. Proc Natl Acad Sci U S A 80(4):901-905

Jones OAH, Swain SC, Svendsen C, Griffin JL, Sturzenbaum SR, Spurgeon DJ (2012) Potential new method of mixture effects testing using metabolomics and Caenorhabditis elegans. J Proteome Res 11(2):1446-1453

Kanfer JG, Ashwell JJ, Burns JJ (1960) Formation of 1-lyxonic and 1xylonic acids from 1-ascorbic acid in rat kidney. J Biol Chem 235: $2518-2521$

Khodayari S, Moharramipour S, Larvor V, Hidalgo K, Renault D (2013) Deciphering the metabolic changes associated with diapause syndrome and cold acclimation in the two-spotted spider mite Tetranychus urticae. PLoS ONE 8(1):e54025

Klein M, Levski S, Keren S (1982) Comparative toxicity of several insecticides to eggs, larvae and adults of the Egyptian cottonworm, Spodoptera littoralis, in laboratory trials. Phytoparasitica 10(1):1320

Kokushi E, Uno S, Pal S, Koyama J (2013) Effects of chlorpyrifos on the metabolome of the freshwater carp. Cyprinus carpio Environ Toxicol. doi: 10.1002/tox.21903

Liang YJ, Wang HP, Yang L, Li W, Wu YJ (2012a) Metabonomic responses in rat urine following subacute exposure to propoxur. Int $\mathrm{J}$ Toxicol 31(3):287-93

Liang YJ, Wang HP, Long DX, Wu YJ (2012b) (1)H NMR-based metabonomic profiling of rat serum and urine to characterize the subacute effects of carbamate insecticide propoxur. Biomarkers 17(6):566-74

Limmer S, Weiler A, Volkenhoff A, Babatz F, Klämbt K (2014) The Drosophila blood-brain barrier: development and function of a glial endothelium. Front Neurosci 8(365):1-19

Lurling M, Scheffer M (2007) Info-disruption: pollution and the transfer of chemical information between organisms. Trends Ecolo Evol 22(7):374-379

Mayer F, Mayer N, Chinn L, Pinsonneault RL, Kroetz D, Bainton RJ (2009) Evolutionary conservation of vertebrate blood-brain barrier chemoprotective mechanisms in Drosophila. J Neurosci 29(11): $3538-3550$

McKelvie JR, Wolfe DM, Celejewski MA, Alaee M, Simpson AJ, Simpson MJ (2011) Metabolic responses of Eisenia fetida after 
sub-lethal exposure to organic contaminants with different toxic modes of action. Environ Pollut 159(12):3620-6

Miles M, Lysandrou M (2002) Evidence for negative cross resistance to insecticides in field collected Spodoptera littoralis (Boisd.) from Lebanon in laboratory bioassays. Meded Rijksuniv Gent Fak Landbouwkd Toegep Biol Wet 67(3):665-9

Moffat C, Pacheco JG, Sharp S, Samson AJ, Bollan KA, Huang J, Buckland ST, Connolly CN (2015) Chronic exposure to neonicotinoids increases neuronal vulnerability to mitochondrial dysfunction in the bumblebee (Bombus terrestris). FASEB J 29(5): 2112-9. doi:10.1096/fj.14-267179

Mudiam MK, Ch R, Saxena PN (2013) Gas chromatography-mass spectrometry based metabolomic approach for optimization and toxicity evaluation of earthworm sub-lethal responses to carbofuran. PLoS ONE 8(12):e81077

Naqvi SM, Vaishnavi C (1993) Bioaccumulative potential and toxicity of endosulfan insecticide to non-target animals. Comp Biochem Physiol C 105(3):347-61

Nath BS (2003) Shifts in glycogen metabolism in hemolymph and fat body of the silkworm. Pestic Biochem Physiol 74(2):73-84

Nemoto H (1984) Factors inducing resurgence in the diamondback moth after application of methomyl. Proceedings of the second international workshop. Asian vegetable research development center, Tainan, pp 91-97

Party V, Hanot C, Büsser DS, Rochat D, Renou M (2013) Changes in odor background affect the locomotory response to pheromone in moths. PLoS One 8(1):e52897. doi:10.1371/journal.pone.0052897

Paudyal BP (2008) Organophosphorus poisoning. J Nepal Med Assoc 47(172):251-8

Pérez CJ, Alvarado P, Narváez C, Miranda F, Hernández L, Vanegas H, Hruska A, Shelton M (2000) Assessment of insecticide resistance in five insect pests attacking field and vegetable crops in Nicaragua. J Econ Entomol 93(6):1779-1787

Pottier MA, Bozzolan F, Chertemps T, Jacquin-Joly E, Lalouette L, Siaussat D, Maïbèche-Coisne M (2012) Cytochrome P450s and cytochrome P450 reductase in the olfactory organ of the cotton leafworm Spodoptera littoralis. Insect Mol Biol 21(6):568-80. doi: 10.1111/j.1365-2583.2012.01160.x

Ramesh M, Saravanan M (2008) Haematological and biochemical responses in a freshwater fish Cyprinus carpio exposed to chlorpyrifos. Int J Integr Biol 3:80-83

Ríos-Díez JD, Saldamando-Benjumea CI (2011) Susceptibility of Spodoptera frugiperda (Lepidoptera: Noctuidae) strains from central Colombia to two insecticides, methomyl and lambdacyhalothrin: a study of the genetic basis of resistance. J Econ Entomol 104(5):1698-705

Ripper WE (1956) Effects of pesticides on balance of arthropod populations. Annu Rev Entomol 1:403-438
Riskallah MR (1980) Reduced sensitivity of cholinesterase as a factor of resistance in leptophos selected strain in the Egyptian cotton leafworm. J Environ Sci Health B 15(2):181-92

Rosenheim JA, Hoy MA (1988) Sublethal effects of pesticides on the parasitoid Aphytis melinus (Hymenoptera: Aphelinidae). J Econ Entomol 81(2):476-483

Ross DC, Brown TM (1982) Inhibition of larval growth in Spodoptera frugiperda by sublethal dietary concentrations of insecticides. J Agric Food Chem 30(1):193-195

Saleem MA, Ahmad M, Ahmad M, Aslam M, Sayyed AH (2008) Resistance to selected organochlorine, organophosphate, carbamate and pyrethroid, in Spodoptera litura (Lepidoptera: Noctuidae) from Pakistan. J Econ Entomol 101(5):1667-75

Smagghe G, Decombel L, Carton B, Voigt B, Adam G, Tirry L (2002) Action of brassinosteroids in the cotton leafworm Spodoptera littoralis. Insect Biochem Mol Biol 32:199-204

Stark J, Banks J (2003) Population level effects of pesticides and other toxicants on arthropods. Annu Rev Entomol 48:505-519

Syromyatnikov MY, Lopatin AV, Starkov AA, Popov VN (2013) Isolation and properties of flight muscle mitochondria of the bumblebee Bombus terrestris (L.). Biochemistry (Mosc) 78(8):909-14. doi:10.1134/S0006297913080075

Thompson SN (2003) Trehalose - the insect 'blood' sugar. Adv Insect Physiol 31:205-285

Tong H, Su Q, Zhou X, Bai L (2004) Field resistance of Spodoptera litura (Lepidoptera: Noctuidae) to organophosphates, pyrethroids, carbamates and four newer chemistry insecticides in Hunan, China. J Pest Sci 2013;86:599-609

Tricoire-Leignel H, Thany SH, Gadenne C, Anton S (2012) Pest insect olfaction in an insecticide-contaminated environment: infodisruption or hormesis effect. Front Physiol Invertebr Physiol 3:1-6

Tripathi G, Sharma BM (2005) Effects of habitats and pesticides on aerobic capacity and survival of soil fauna. Biomed Environ Sci 18(3):169-75

Vandenbrouck T, Jones OAH, Dom N, Griffin JLand De Coen W (2010) Mixtures of similarly acting compounds in Daphnia magna: from gene to metabolite and beyond. Environmental 36(3):254-268

Van Erp S, Booth L, Gooneratne R, O'Halloran K (2002) Sublethal responses of wolf spiders (Lycosidae) to organophosphorus insecticides. Environ Toxicol 17:449-56

Van Scoy AR, Yue M, Deng X, Tjeerdema RS (2013) Environmental fate and toxicology of methomyl. Rev Environ Contam Toxicol 222:93109

Venables WN, Ripley BD (2000) Modern applied statistics with S-Plus, p176

WHO (1983) World Health Organization data sheet on pesticides No. 55 Methomyl Date issued: VBC/DS/82.55

Zhu F et al (2012) RNA interference of NADPH-cytochrome P450 reductase results in reduced insecticide resistance in the Bed Bug, Cimex lectularius. PLoS ONE 7(2):e31037 